\title{
BROWN TUMOR AT THE JAW IN PATIENTS WITH SECONDARY HYPERPARATHYROIDISM DUE TO CHRONIC RENAL FAILURE
}

\begin{abstract}
Petia F. Pechalova ${ }^{1}$, Elena G. Poriazova ${ }^{2}$
Medical University, Plovdiv, Bulgaria: Faculty of Dental Medicine, Department of Maxillo-facial Surgery ${ }^{1}$, Faculty of Medicine, Department of Pathology²

Summary: Brown tumors are bony lesions caused by rapid osteoclastic activity, which rare involved jaws. Renal osteodystrophy (ROD) is associated with different pathogenetic mechanisms - disorder of calcium-phosphate metabolism, impaired metabolism of vitamin $\mathrm{D}$, increased parathyroid activity that lead to extreme concentrations of parathormone. The authors report two cases of jaw enlargement in patients received haemodialysis with excessive increase values of alkaline phosphatase and parathormone in serum. The patients were treated surgically with corrective procedures in maxillo-facial area.

ROD of the jaws could be severe complication in dialysis patients with end stage of CKD if no appropriate care aimed at correction or prevention of parathyroid hyperfunction was applied to them.
\end{abstract}

Key words: Brown tumor; Renal osteodystrophy; Jaw; Haemodialysis; Alkaline phosphatase; Parathormone

\section{Introduction}

Brown tumors are bony lesions caused by rapid osteoclastic activity and peritrabecular fibrosis due to hyperparathyroidism (HPT) resulting in a locally destructive phenomenon. Actually they represent a reparative cellular process rather than a true neoplasia $(6,12)$. They are known to occur only in the setting of HPT, and are considered the most pathognomonic skeletal changes that accompany this disease (12). At skeletal sites excess parathyroid hormone can lead to a condition called osteitis fibrosa cystica. Osteitis fibrosa cystica is a diffuse resorptive process of the bone resulting from both primary and secondary hyperparathyroidism. The bone-disease component of chronic kidney disease with mineral and bone disorder (CKD-MBD) may result in fractures, bone pain, deformities in growing children, reduced growth velocity, and abnormal height. The term renal osteodystrophy (ROD) is often used in a generic sense to include skeletal disorders of patients with chronic renal failure (14). Patients with more advanced stages of CKD (stages 3-5D), in whom the biochemical abnormalities of mineral metabolism that define CKD-MBD are present, have renal osteodystrophy. The traditional types of ROD have been defined on the basis of turnover and mineralization as follows: mild, slight increase in turnover and normal mineralization; osteitis fibrosa, increased turnover and normal mineralization; osteomalacia, decreased turnover and abnormal mineralization; adynamic, decreased turnover and acel- lularity; mixed, increased turnover with abnormal mineralization. ROD is associated with different pathogenetic mechanisms - disorder of calcium-phosphate metabolism, impaired metabolism of vitamin $\mathrm{D}$, increased parathyroid activity that lead to extreme concentrations of parathormone (9). X-ray characteristics of bone pathology in renal osteodystrophy are associated with demineralization, loss of lamina dura, trabecular pattern with a 'ground-glass' appearance (3). Clinical characteristics of jaw pathology present with asymptomatic macrognathia (localized or diffuse) (1), tooth mobility in the region, abnormal occlusion, changes in tooth enamel and pulp (5).

Bone changes in ROD are characterized with typical skeletal locations - metacarpals, phalanges, skull, pelvis, clavicle, ribs, femur, spine, rarely jaws and the sphenoid sinus (8), which give us grounds to describe the two new cases observed and treated by us.

\section{Cases reports}

Patient No. 1 was a male, 19 years old. He received haemodialysis treatment for 6 years, three times a week, for chronic renal failure - end stage, with established secondary hyperparathyroidism. Local status revealed diffuse enlargement of the maxilla, accompanied by smoothening of hard palate and fan-like divergence of teeth. In lingual aspect, on the mandible, from the first premolars on the right side to the central incisor on the left side, a formation $5 \mathrm{~cm}$ in diameter, having bone-like density, painless 
Tab. 1: Blood tests of patients showing abnormalities

\begin{tabular}{|c|c|c|c|c|}
\hline \multirow{2}{*}{ Indicator } & \multirow{2}{*}{ Patient No. 1} & \multirow{2}{*}{ Patient No. 2} & \multicolumn{2}{|l|}{ Normal range } \\
\hline & & & males & females \\
\hline Hemoglobin & $111 \mathrm{~g} / 1$ & $115 \mathrm{~g} / 1$ & $140-180 \mathrm{~g} / 1$ & $120-160 \mathrm{~g} / 1$ \\
\hline Red blood cells & $3.85 \times 10^{12} / 1$ & $3.42 \times 10^{12 / 1}$ & $4.5-6.0 \times 10^{12} / 1$ & $3.9-5.3 \times 10^{12 / 1}$ \\
\hline Hematocrit & 0.354 & 0.338 & $0.40-0.54$ & $0.36-0.47$ \\
\hline Triglicerides & 2.27 & 4.79 & \multicolumn{2}{|l|}{$0.60-1.70$} \\
\hline Urea & $8.6 \mathrm{mmol} / 1$ & $13.6 \mathrm{mmol} / 1$ & $3.2-8.2 \mathrm{mmol} / 1$ & $2.6-7.2 \mathrm{mmol} / 1$ \\
\hline Creatinine & $431 \mu \mathrm{mol} / 1$ & $396 \mu \mathrm{mol} / 1$ & $74-134 \mu \mathrm{mol} / 1$ & $44-96 \mu \mathrm{mol} / 1$ \\
\hline $\begin{array}{l}\text { Alkaline } \\
\text { phosphatase }\end{array}$ & $2204 \mathrm{U} / 1$ & $3227 \mathrm{U} / 1$ & \multicolumn{2}{|l|}{ 98-279 U/1 } \\
\hline Parathormone & $1409.3 \mathrm{pg} / \mathrm{ml}$ & $2595.8 \mathrm{pg} / \mathrm{ml}$ & \multicolumn{2}{|l|}{$12-88 \mathrm{pg} / \mathrm{ml}$} \\
\hline
\end{tabular}

at palpation, covered with mucosa with normal colour and tissue tone was found.

The results of blood tests are given in Table 1 .

The results from the examination of dental pulp vitality in the region of the formation showed necrosis of central incisors on the left and on the right side, damage of the pulp of the second incisor, canine and first premolar on the right side. Computed-tomography scan of the skull and facial bones without amplification showed thickening of the bones of the skull with diffuse hypodense lesions in the diploe, 1 by $1 \mathrm{~mm}$ in size and most manifested dysplastic changes in the mandible, which visualized enlarged and with altered density characteristic (400-500 HE) - Figure 1 .

Surgical treatment was performed under general anaesthesia. Raising a mucoperiostal flap revealed the thinned cortical bone plate (having thickness of parchment) and the underlying soft tissue formation, heavily bleeding, with porous surface, which separated without any difficulty from the surrounding normally looking bone, after which the cavity formed in bone (Figure 2) could be seen. Neither tooth roots nor mandibular canal were encountered due to the intact bone bottom of the cavity. The flap was adapted and stitched. The surgical wound healed by primary intention healing.

Histological finding (Figure 3) showed morphological evidence of secondary osteodystrophy - fibrous and bone tissue with cystic and degenerative changes, osteoclastic giant cells and bleeding, thus confirming the clinical finding.

Patient No. 2 was a woman at the age of 49 . She received haemodialysis treatment for 6 years, three times a week, for chronic renal failure - end stage. No examination for secondary hyperparathyroidism was performed.

Local intraoral examination found formations having bone-like density located in vestibular aspect bilaterally in the region of the maxillary premolars and molars, asymptomatic, covered with mucosa with normal colour and tissue tone, causing aesthetic discomfort (Figure 4) and tooth mobility in the region around them.
The results of blood tests are given in Table 1.

The performed computed-tomography scan of facial skull showed pathological changes of all bone structures visualized in the study, with enlargement of the maxilla, which was visualized as having porous, cystic bone re-organization and thinned corticalis (Figure 5).

Surgical treatment was performed under general anaesthesia, consecutively for both sides, in one operation. Intraoperatively, thinning of cortical vestibular bone plate of the maxilla was found bilaterally over massive soft tissue formations, heavily bleeding, poorly demarcated from the surrounding bone, which had altered macroscopic structure and reduced density. The roots of some teeth presented in the formation devoid of bone support and therefore they were removed. The surgical wounds healed by primary intention healing.

Histological examination of the preparations from both sides of the maxilla showed that this was material characterized by bone beams, fibrosis, giant cells of ,osteoclast” type, cysts with haemorrhage, and it confirmed the clinical findings.

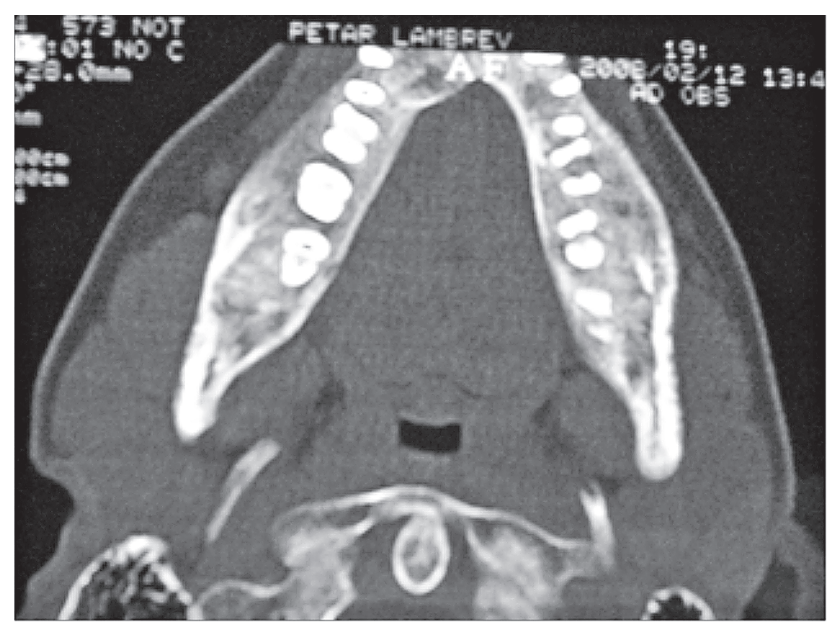

Fig. 1: Computer tomography of patient No. 1 


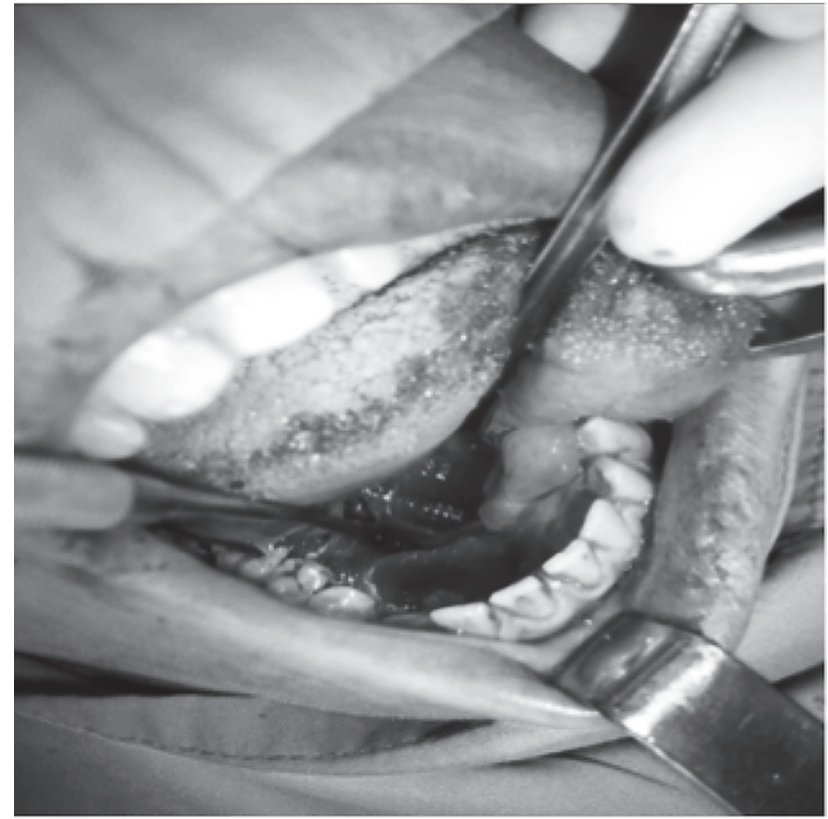

Fig. 2: Patient No. 1-intraoperative finding

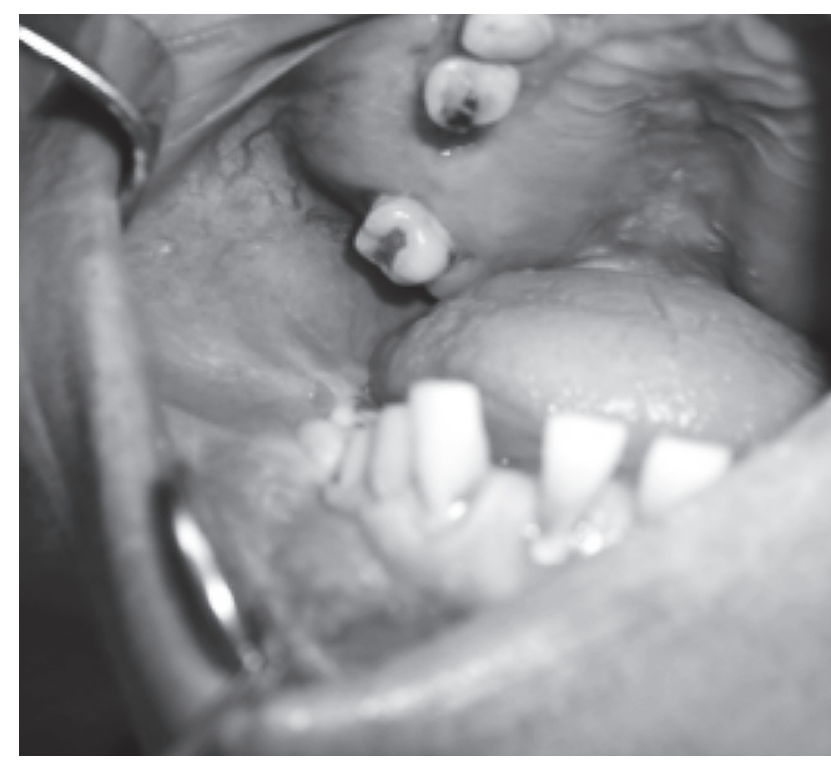

Fig. 4: Patient No. 2- preoperative status

\section{Discussion}

In literature reports about ROD in maxillo-facila area are rare. Reports both for patients on long dialysis treatment (4) and for development of deformity after 6-7 years of dialysis can be found $(7,10)$. Andreades et al. (2) reported a brown tumor in a patient with renal disease not treated with dialysis.

ROD is a complex disorder and biochemical assays do not adequately predict the underlying bone histology.

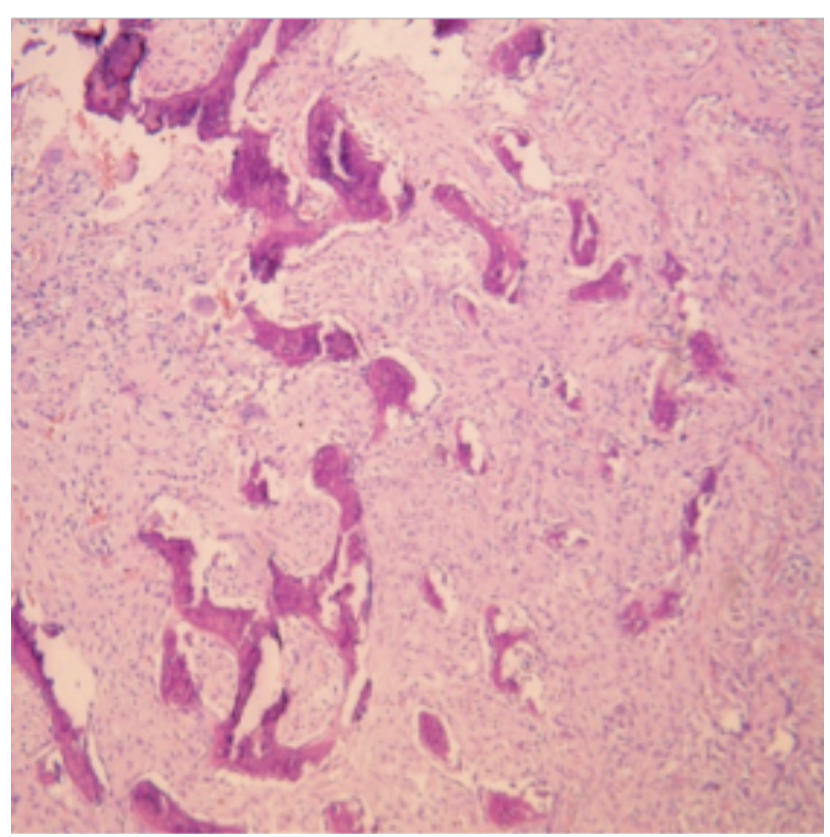

Fig. 3: Histological image

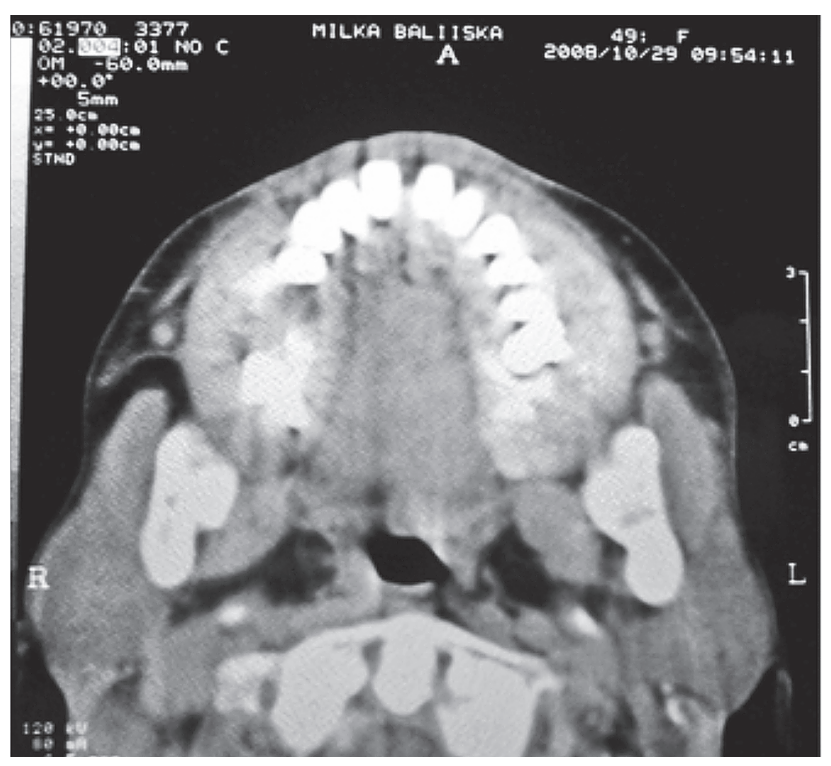

Fig. 5: Computer tomography of patient No. 2

CKD-MBD can lead to an abnormal bone quality even in the setting of a normal or high bone-mineral content, and the gold standard diagnosis for the bone component of $\mathrm{CKD}-\mathrm{MBD}$ is bone biopsy-based histologic analysis. Bone biopsies in patients with CKD should be characterized by determining bone turnover, mineralization, and volume (TMV). In patients with CKD stages $3-5 \mathrm{D}$, with evidence of CKD-MBD, BMD testing not be performed routinely, because BMD does not predict the type of renal osteodystrophy but measurements of serum PTH or bone- 
specific alkaline phosphatase can be used to evaluate bone disease because markedly high or low values predict underlying bone turnover (11). In the patients observed by us the values of alkaline phosphatase (2204 UI/1 for the first patient, and $3227 \mathrm{UI} / 1$ for the second patient) and parathormone $(1409.3 \mathrm{pg} / \mathrm{ml}$ for the first patient, $2595.8 \mathrm{pg} / \mathrm{ml}$ for the second patient) were significantly increased.

Brown tumors can occur as solitary or multiple lesions in any bone. These tumors are usually soft, painless, minimally tender, and appear elastic on palpation. Symptoms result from the considerable dimensions of the tumor and its localization, but in most cases maxillary tumor is not painful. Radiographically, they appear as well demarcated monolocular or multilocular osteolytic lesions. In the mandible, the cortical bone is expanded and thinned $(12,14)$. Brown tumors of the jaws occasionally result in root resorption and loss of the lamina dura and may present as a space occupying mass in the sinus (17). When a brown tumor involves the face and has progressive growth, it may cause severe deformities, discomfort, alteration of the masticatory apparatus, and difficulty to breathe through (13).

Regarding the treatment of patients with ROD of the jaws, two approaches are recommended. The first one is managing of hyperparathyroidism $(7,13,16)$ :

- conservatively - limiting the intake of dietary phosphates; by the means of drugs - phosphate-binding drugs, vitamin D analogues, calcium mimetics;

- surgically - by parathyroidectomy and waiting until reduction in the size of jaws

Proponents of the second approach assume that jaws do not restore their normal contours after treatment of hyperparathyroidism, which requires corrective surgery (15) - an opinion supported by the authors.

In conclusion, these cases illustrate how severe complication could be ROD in the jaws, if no appropriate care, aimed at correction or prevention of parathyroid hyperfunction, was applied to dialysis patients with end stage of CKD. Jaw enlargement tends to cease after the correction of the secondary hyperparathyroidism, however, sometimes surgery is necessary.

\section{References}

1. Adornato MC and Mayne RW. Macrognathia of renal osteodystrophy in a dialysis patient. Report of a case. NY State Dent J 2000; 66: 30-34.

2. Andreades D, Belazi M, Antoniades D. Diagnosis of a maxillary brown tumor associated with hyperparathyroidism secondary to chronic renal failure - a case report. Oral Health Prev Dent 2004; 2: 143 - 147.

3. Antonelli JR and Hottel TL. Oral manifestations of renal osteodystrophy: case report and review of the literature. Spec Care Dentist 2003; 23: 28-34.

4. Daneshbod Y. Renal ostedystrophy of the palate. N Engl J Med 2008; 359: 74

5. De Rossi SS and Glick M. Dental considerations both the patient with renal disease receiving hemodialysis. JADA 1996; 127: 211-219.

6. Fineman I, Johnson JP, di Patre PL, Sandhu H. Chronic renal failure causing brown tumors and myelopathy. J Neurosurg (Spine 2) 1999; 90: 242-6.

7. Hata T, Irei I, Tanaka K, Nagatsuka H, Hosoda M. Macrognathia secondary to dialysis-related renal osteodistrophy treated successfully by parathyroidectomy. Int J Oral and Maxillofac Surg 2006; 35: 378-382.

8. Hoshi M, Takami M, Kajikawa M, et al. A case of multiple skeletal lesions of brown tumors, mimicking carcinoma metastases. Arch Orthop Trauma Surg 2008; 128: 149-154.

9. Hruska K. Pathophysiology of renal osteodystrophy. Pediatr Nephrol 2000; 14: 636-640.

10. Kalyvas D, Tosios KI, Leventis MD, Tsiklakis K, Angelopoulos AP. Localized jaw enlargement in renal osteodystrophy: report of a case and review of the literature. Oral Surg Oral Med Oral Pathol Oral Radiol Endod 2004; 97: 68-74.

11. Kidney International 2009; 76 (Suppl 113), S22-S49 (doi:10.1038/ki.2009.191).

12. Leal CTS, Lacativa PGS, Gomes EMS, Nunes RC, de S. Costa FLF, Gandelmann IHA, et al. Surgical approach and clinical outcome of a deforming brown tumor at the maxilla in a patient with secondary hyperparathyroidism due to chronic renal failure. Arq Bras Endocrinol Metab 2006; 50: 963-7.

13. Morrone LF, Ettore GC, Passavati G, et al. Maxillary brown tumor in secondary hyperparathyroidism requiring urgent parathyroidectomy. J Nephol 2001; 14 : 415-9.

14. Park JW, Choi BR, Gang TI, et al. Mandibular brown tumor in renal osteodystrophy. Korean Journal of Oral and Maxillofacial Radiology 2008; 38: 229-31.

15. Phelps KR, Bansal M, Twersky J. Jaw enlargement complicating secondary hyperparathyroidism in three hemodialysis patients. Clin Nephrol 1994; 41: 173-179.

16. Saliba W, El-Haddad B. Secondary hyperparathyroidism: Pathophysiology and treatment. The Journal of the American Board of Family Medicine 2009; 22 (5): 574-581

17. Triantafillidou K, Zouloumis L, Karakinaris G, Kalimeras E, Iordanidis F. Brown tumors of the jaws associated with primary or secondary hyperparathyroidism. A clinical study and review of the literature.Am J Otolaryngol 2006; 27 : $281-6$.

Received: 07/12/2011

Accepted in revised form: 22/03/2013

\section{Corresponding author:}

Petia F. Pechalova, Plovdiv, Bulgaria, Department of Maxillo-facial Surgery, Faculty of Dental Medicine, Medical University, Str. "Peshtersko shose" No.66; e-mail: pechalova@abv.bg 